\title{
Biomarkers for exposure to dietary flavonoids: a review of the current evidence for identification of quercetin glycosides in plasma
}

\author{
A. J. Day and G. Williamson* \\ Diet, Health and Consumer Sciences Division, Institute of Food Research, \\ Norwich Research Park, Colney, Norwich NR4 7UA, UK
}

\begin{abstract}
Quercetin, a polyphenol with potential health effects, is absorbed by humans and measurement in plasma can be used as a biomarker for intake. However, the chemical nature of the quercetin in blood is still not known, although one possibility is that glucosides are found in an unchanged form from the original food. We propose that the existence of quercetin glucosides in plasma is unlikely, since the metabolic $\beta$-glucosidase capacity of the small intestine and of the liver is too great for quercetin glucosides to escape deglycosylation. We critically examine the limited number of studies which purport to detect quercetin glycosides in blood and the current evidence for the absorption of these compounds from the gastrointestinal tract. We emphasise the need for comprehensive identification of circulating compounds, since polyphenol glucuronides, the expected metabolites in plasma, have almost identical chromatographic properties to the glucosides at acid $\mathrm{pH}$. Studies on the nature of quercetin metabolites in plasma are urgently needed so that the proposed biological activities of quercetin can be re-assessed and that a suitable biomarker of exposure can be established.
\end{abstract}

Quercetin glucoside: Human metabolism: Deglycosylation: Rutin: Polyphenol

There are many reports in the literature on the possible biological effects of dietary flavonoids such as quercetin. However, there is serious lack of fundamental knowledge on the uptake and metabolism of these molecules in humans. Most biological activities have been measured with free quercetin (the aglycone) because of its ready availability, regardless of the limited amount in the diet compared to the naturally occurring glycosides. Evidence shows that quercetin conjugates have very different activities compared to those of the parent aglycone (Williamson et al. 1996; Morand et al. 1998). It is, therefore, imperative that the structures of the metabolites are correctly identified in order to test and re-assess biological activities, determine pharmacokinetics and to quantify dietary exposure.

Several studies have now shown that quercetin derivatives are found in the plasma after consumption of flavonoid-rich foods in volunteers (Hollman et al. 1997; de Vries et al. 1998; Janseen et al. 1998; Manach et al. 1998; Young et al. 1999). Methods to analyse polyphenols in urine and plasma employ gas chromatography, or HPLC with various detectors such as UV spectra, fluorescence, mass spectrometry or electrochemistry. However, results have not been validated between laboratories, and studies are additionally hampered by lack of knowledge on metabolites in humans. It is also very difficult to obtain, use and quantify appropriate standards, especially of the metabolites. Most studies involve enzymic or chemical pre-treatment to convert quercetin metabolites into the parent aglycone, i.e. free quercetin or methylated quercetin (either isorhamnetin, $3^{\prime}$-methyl; or tamarixetin, $4^{\prime}$-methyl), which can be analysed and quantified chromatographically. Unfortunately information on the chemical nature of the metabolites is lost during pretreatment. Consequently research is now focusing on attempting to identify the quercetin metabolites, including the nature and number of the conjugating groups (methyl, sulphate and glucuronide) and the position of these groups on the polyphenol. Although there is considerable evidence for uptake, the chemical species of quercetin in vivo remains unknown. In this paper we review evidence for the absorption of quercetin glycosides and demonstrate the difficulty in distinguishing quercetin metabolites from the parent quercetin glycosides when analysed by HPLC with UV diode array detection.

\section{Deglycosylation}

Flavonols in the diet are glycosylated, and depending on the nature and position of the sugar residue, absorption can occur in the small intestine (Hollman et al. 1997, 1999), although the mechanism is not understood. It is possible that a transporter, such as the sodium-dependent glucose transporter (SGLT1), may be able to transport some flavonol glucosides as an interaction has been shown (Gee et al. 1998). However, the largest compounds

\footnotetext{
* Corresponding author: G. Williamson, fax +44 (0) 1603 507723, email gary.williamson@bbsrc.ac.uk
} 
transported by this mechanism (e.g. $\beta$-napthyl glucoside) are smaller than the flavonoid glycosides (PanayotovaHeiermann et al. 1996) and phloridzin, a related flavonoid, interacts as a classical inhibitor of SGLT1 (Hirayama et al. 1996). High levels of $\beta$-glucosidase activity exist in human and rat small intestine epithelial cells (Day et al. 1998; Ioku et al. 1998) and liver (Day et al. 1998). This activity is attributed to a broad-specificity cytosolic $\beta$ glucosidase (Lambert et al. 1999) present in both tissues, and lactase phloridzin hydrolase (LPH; Day et al. 2000), found on the brush-border of the small intestine. If SGLT1 transports the flavonol glucoside, the cytosolic $\beta$ glucosidase can hydrolyse most glucosides, although quercetin-3-glucoside and quercetin-3-rutinoside (rutin) are not substrates. LPH can hydrolyse a broad range of flavonoid glucosides as shown in Fig. 1, but rutin was not a substrate for this enzyme. As LPH acts directly within the gut lumen, the released aglycone can diffuse across the gut wall. Within the enterocyte, conjugation of the aglycone will occur rapidly forming mainly the glucuronides and sulphates.

\section{Identification by UV absorption spectra}

UV spectra provide some detail for the identification of flavonols as shown in Fig. 2 and reviewed extensively by Mabry et al. (1970). The flavonol spectrum consists of two bands, I and II; if the 3-hydroxyl group of a flavonol is conjugated, a hypsochromic shift (to a shorter wavelength) occurs. Free quercetin exhibits band I absorption at $370 \mathrm{~nm}$, whereas 3-glycosylation shifts band I to around $355 \mathrm{~nm}$. Fig. 2 also demonstrates that the nature of the sugar substitution does not effect the absorption spectrum, and hence identification of the glucoside or glucuronide based on this evidence is not possible.

Identification of flavonols from biological samples

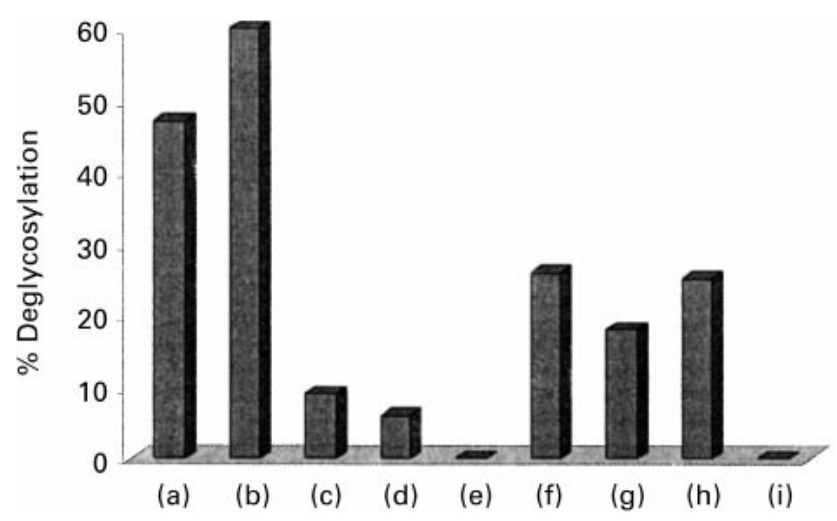

Fig. 1. Deglycosylation of flavonoid glycosides by lactase phloridzin hydrolase (LPH) isolated from sheep small intestine (Rivera-Sagredo et al. 1992): (a) quercetin-3-glucoside, (b) quercetin-4'-glucoside, (c) quercetin-3,4'-diglucoside, (d) $3^{\prime}$-methylquercetin-3-glucoside, (e) quercetin-3-rutinoside, (f) genistein-7-glucoside, (g) daidzein-7glucoside, (h) phloridzin, (i) naringenin-7-rhamnoglucoside. Compounds $(100 \mu \mathrm{M})$ were incubated for $20 \mathrm{~min}\left(1 \mu \mathrm{g} \mathrm{LPH}, 37^{\circ} \mathrm{C}, \mathrm{pH}\right.$ 6, $50 \mathrm{~mm}$ sodium phosphate buffer) with the aglycone formed monitored by HPLC with diode array $(270$ and $370 \mathrm{~nm}$, see Fig. 3).

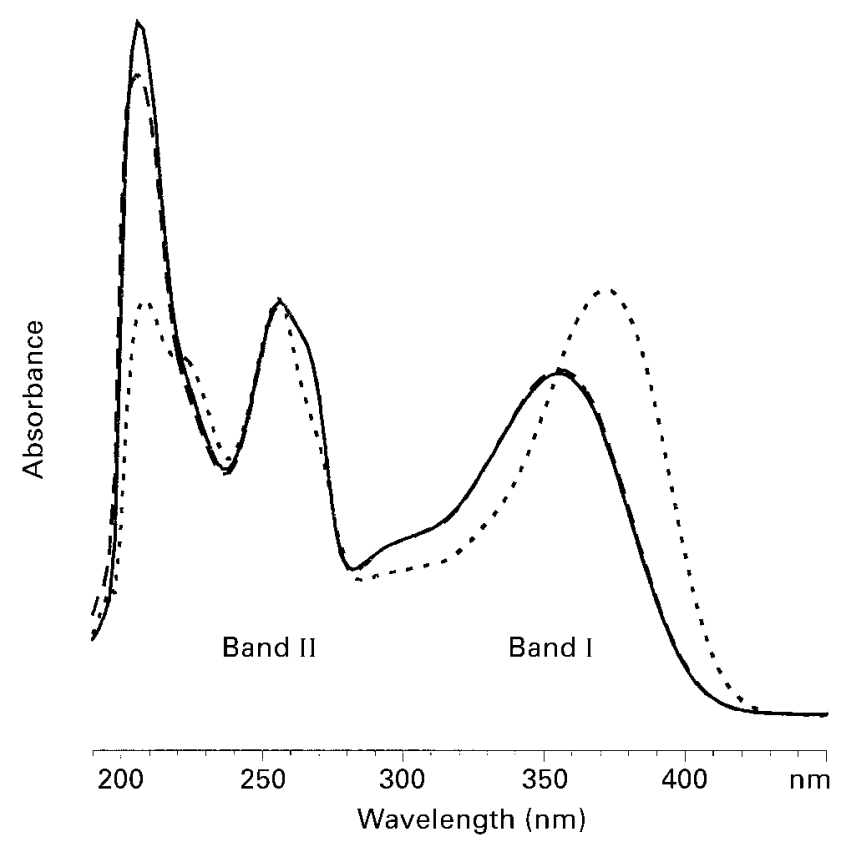

Fig. 2. UV-absorption spectra of quercetin and quercetin conjugates in methanol. ..., quercetin; -, quercetin-3-glucoside; ----, quercetin-3-glucuronide.

becomes a major problem when relying on HPLC data with diode array detection. Not only are physiological levels likely to be near the limit of detection, but the retention times can shift due to residual protein present in samples. Problems in possible misidentification are highlighted by a paper from Paganga \& Rice-Evans (1997) in which detection of flavonol glycosides in plasma was suggested by evidence based on HPLC elution times and UV-spectra from on-line diode array. Rutin was identified in the two plasma samples analysed; however, as the retention time shifted 0.4 min between samples, and quercetin-3-sulphate and mixed sulphate-glucuronide conjugates of quercetin and $3^{\prime}$-methylquercetin also elute around this time, positive proof was not provided for the true identification of the circulating flavonol species observed in this study. Furthermore, the concentration of quercetin glycosides (including rutin) is higher $(4.57 \mu \mathrm{M})$ than observed after a meal rich in flavonol glycosides (0.37 $\mu \mathrm{M}$; Manach et al. 1998), or after a high intake of onion for several days (1.5 $\mu \mathrm{M}$; Janseen et al. 1998). Phloridzin was also tentatively identified in the plasma, which is unlikely due to the low concentration found in the diet (Price et al. 1999), the inability to be transported by SGLT1 (Lostao et al. 1994) and the rapid deglycosylation and glucuronidation by the small intestine (Mizuma \& Awazu, 1998). It is more likely that phloretin glucuronide or some other dihydrochalcone was observed.

\section{Identification by elution time}

Further research showed the presence of intact flavonol glucosides in human plasma after consumption of onions 
(Aziz et al. 1998). Quercetin-4'-glucoside and 3'-methylquercetin- $4^{\prime}$-glucoside (both present in onion) were identified by retention time and co-elution with standards. The method employed was based on post-column derivatisation of the flavonol with aluminium for detection by fluorescence (Hollman et al. 1996). This method is particularly sensitive and is excellent for identifying low levels of flavonols in biological samples, although a free 3-hydroxyl group for chelation with aluminium is required. Hence, it appears reasonable that the presence of fluorescentderivatised compounds in the plasma samples are the same as the standard flavonol glucosides eluting at the same retention time. However, no standards of the flavonol glucuronides were compared.

Fig. $3 \mathrm{a}$ is an HPLC chromatogram showing the elution profile of quercetin glucosides in a methanol extract of yellow onion (Rijnsburger); the order for elution of the quercetin glucosides was quercetin-3, $4^{\prime}$-diglucoside (7.7 min), quercetin- $4^{\prime}$-glucoside $(13.8 \mathrm{~min})$ and $3^{\prime}$ methylquercetin- $4^{\prime}$-glucoside $(14.4 \mathrm{~min})$, which is in agreement with others (Park \& Lee, 1996). A mixture of quercetin glucuronides can be made by incubation of quercetin with UDP-glucuronosyltransferase (e.g. using rat microsomes) in the presence of UDP-glucuronic acid. Fig. 3(b) shows the elution profile of the quercetin glucuronides formed, also shown by Morand et al. (1998), using the same HPLC conditions as for the onion extract. The retention time of $3^{\prime}$-methylquercetin$4^{\prime}$-glucoside is almost identical to that of quercetin- $4^{\prime}$ glucuronide, highlighting the potential problems of misidentification based on retention times without reference to metabolic standards. It should be noted that the three quercetin glucuronides shown in Fig. 3b should fluoresce when derivatised with aluminium as they are not conjugated at the 3-position. Although Aziz et al. may well have identified flavonol glucosides in human plasma, the evidence presented in their paper is not sufficient. Mass spectra and/or hydrolysis by a specific $\beta$-glucosidase or $\beta$-glucuronidase will provide further proof of the compounds circulating in the plasma.

\section{Absorption of glycosides}

Mauri et al. (1999) determined rutin in human plasma after subjects consumed tomato puree for $14 \mathrm{~d}$. Evidence was obtained by HPLC coupled to negative-ion electrospray, which produced mass ions of 609 and 300, characteristic of rutin under these conditions, and eluted at the appropriate retention time. This is good evidence, but the published
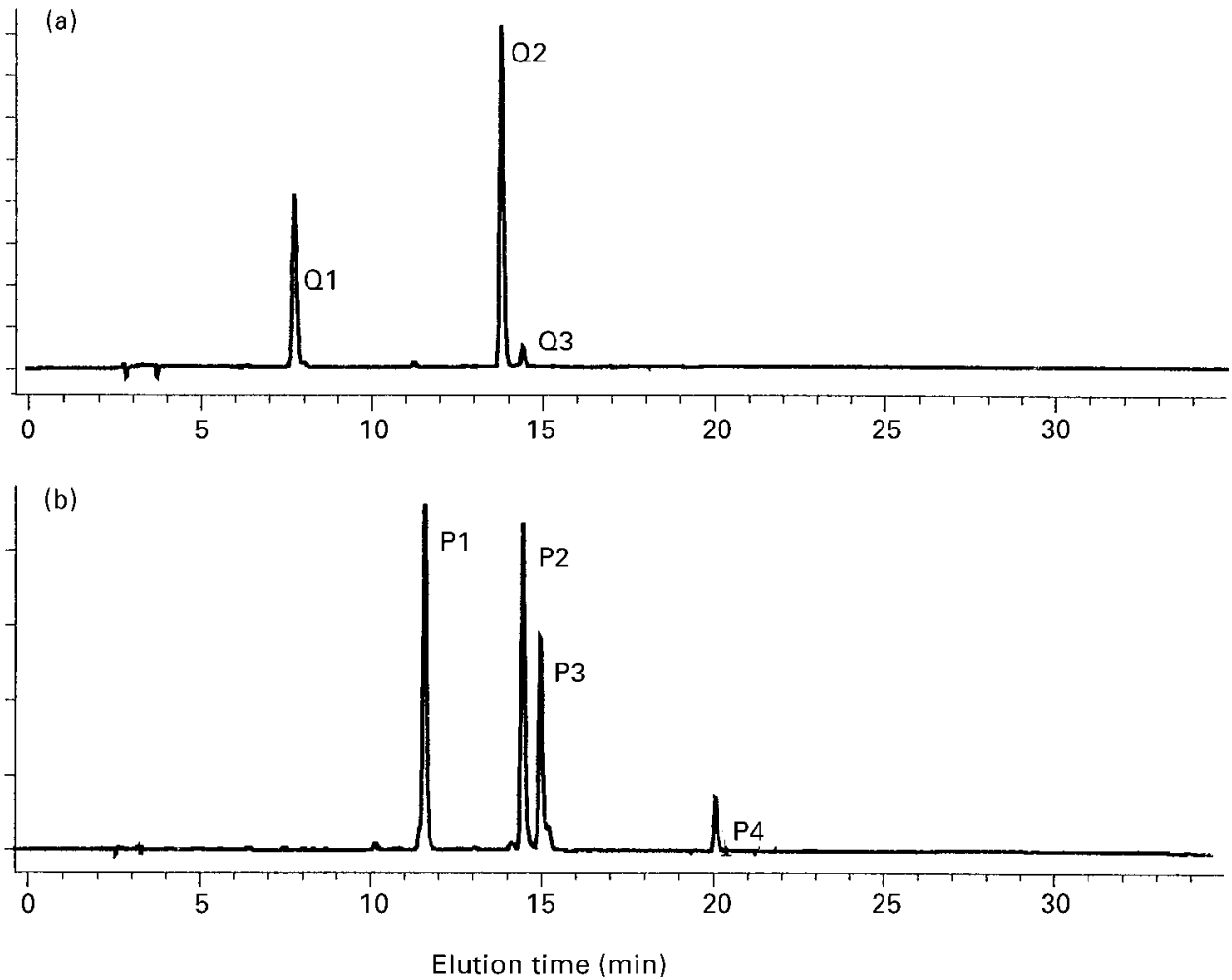

Fig. 3. HPLC chromatogram of (a) methanolic extract of onion; Q1, quercetin-3,4'-diglucoside; Q2, quercetin-4'-glucoside; Q3, 3'methylquercetin-4'-glucoside, (b) quercetin glucuronides (P1, P2, P3) produced in vitro after treatment of quercetin (P4) by UDPglucuronosyltransferase (UDPGT). UDPGT ( $5 \mathrm{mg} / \mathrm{ml}$; bovine, Sigma), UDP-glucuronic acid (2 mM; Sigma) and quercetin (100 $\mu \mathrm{M})$ were incubated for $4 \mathrm{~h}\left(37^{\circ} \mathrm{C}, \mathrm{pH} 7,10 \mathrm{~mm}\right.$ potassium phosphate buffer) followed by analysis by HPLC. Solvents A (water: tetrahydrofuran: trifluoroacetic acid 98:2:0.1) and B (acetonitrile), were run at a flow rate of $1 \mathrm{ml} / \mathrm{min}$, using a gradient of $17 \%$ B (2 min), increasing to $25 \%$ B (5 min), $35 \%$ B (8 min), $50 \%$ B (5 min) and then to $100 \%$ B (5 min). A column clean-up stage maintained B at $100 \%$ (5 min) followed by a reequilibration at $17 \%$ B (15 min). The column was packed with Prodigy $5 \mu \mathrm{m}$ ODS3 reverse-phase silica, $250 \mathrm{~mm}$ by $4.6 \mathrm{~mm}$ internal diameter (Phenomenex, Macclesfield, UK). Diode array detection monitored the eluent at 270 and $370 \mathrm{~nm}$. 
amount that was detected, $1-5 \mu \mathrm{g} / \mathrm{ml}$ in plasma (from $1.7 \mathrm{mg} / \mathrm{d}$ rutin), is too high unless accumulation of rutin in plasma occurred over the period of the study. The actual value for the rutin level in plasma in the study was in the range $0.08-0.3 \mu \mathrm{M}$ (personal communication; P. Pietta, 2000 ), although the concentration is still higher than expected based on previous work $(0 \cdot 1 \mu \mathrm{M}$ after $49 \mathrm{mg} / \mathrm{d}$ quercetin mainly as rutin from tea over $3 \mathrm{~d}$; de Vries et al. 1998).

Quercetin, but not rutin, was absorbed across the rat intestinal wall during in situ perfusion (Crespy et al. 1999a), which is not surprising as hydrophilic compounds generally cannot diffuse across biological membranes (Saija et al. 1995). Quercetin-3-glucoside was absorbed at approximately double the rate of quercetin in the same system (Crespy et al. 1999b), and a rat evertedjejunum model (Gee et al. 2000). In both cases quercetin-3-glucoside was not found after passage across the gut. An in vivo study with rats also showed quercetin metabolites in the blood but no rutin or quercetin-3glucoside after oral dosing of the glycosides (Morand et al. 2000). Spencer et al. (1999), however, found small amounts of rutin and some quercetin-3-glucoside absorbed across an isolated rat perfused intestine. Deglycosylation of quercetin-3-glucoside had occurred, as evident by the aglycone and glucuronide formed, however unlike other flavonoid glucosides tested, a proportion of the glucoside was found in the serosal solution. The differences observed may be accounted for by the experimental model, length of incubation or strain of rat used.

There are several lines of evidence that rutin is absorbed in the colon only after deglycosylation. Rutin, unlike quercetin monoglucosides, did not interact with SGLT1 in the rat (Gee et al. 1998). Peak plasma levels of quercetin in human volunteers were observed at $9.3 \mathrm{~h}$ after a rutin supplement was taken (Hollman et al. 1997), indicating absorption from the colon. In addition, rutin was absorbed in rats at a time corresponding to the colon (Manach et al. 1997). Once rutin has reached the large intestine it will be hydrolysed to quercetin by microflora and subjected to further degradation, producing simple phenolics. Thus, it would seem unlikely that rutin per se can be absorbed. Baba et al. $(1981,1983)$ could not find intact labelled rutin ( $\left.{ }^{2} \mathrm{H}\right]$ quercetin-rutinoside) in human or rat urine; only ring fission products could be observed. Bourne \& Rice-Evans $(1998,1999)$ were also unable to detect rutin in the urine of humans after consuming high levels of tomatoes. If rutin were absorbed, however, the human $\beta$-glucosidase present in the small intestine and liver is not capable of hydrolysing the rhamno-glycosidic bond to the aglycone and hence rutin would be observed in plasma. Biliary excretion of rutin may be the major pathway for elimination of this compound which would account for the lack of detection in the urine.

\section{Positive identification}

In summary, data obtained on the metabolites of quercetin should be closely examined for the reliability of the analytical technique used. In particular, methods based on UV spectra and retention times can provide useful but incomplete data on positive identification of glucosides compared to the glucuronide. Several approaches could be taken to characterise flavonoid metabolites more clearly.

(1) Use of specific highly purified deconjugating enzymes in combination with UV-diode array: often enzyme preparations used for pretreatment of samples contain a mixture of deconjugating enzymes. Unless controls provide absolute evidence that additional activity is not present, positive identification is not possible. However, recombinant enzymes should be easier to purify to a state which is free of residual activity, and these can be used individually to show the presence of glucosides, glucuronides and sulphates.

(2) HPLC with coularray detection: on-line electrochemical detection of compounds using a coularray can provide fingerprint-type information on the nature of a compound. The redox potential of the flavonoid will vary depending on the position, number and type of conjugating group. Appropriate metabolic standards will still be required for positive identification, although elimination of parent compounds is more reliable than with evidence based on retention time and UV-absorbance.

(3) HPLC-MS/MS: tandem mass spectrometry provides the most useful tool currently available for the positive identification of compounds in biological fluids. Under appropriate conditions the mass of the parent metabolite and aglycone are obtained along with specific fragmentation patterns characteristic of conjugation at different positions on the polyphenol.

Furthermore, it is essential to consider the biochemical mechanisms involved in absorption and metabolism when analysing for compounds in biological systems. The ability of flavonoids to be transported into cells, to interact with conjugating or deconjugating enzymes and to be eliminated from the body are important questions that should not be overlooked. For example, although evidence of quercetin glucosides in human plasma has not been established with absolute certainty, the likelihood of significant levels of these compounds being present in plasma is low due to the high activity of human and microbial $\beta$-glucosidases. Any intact flavonoid glycosides in the plasma are unlikely to be conjugated further and so the pathway of excretion may be affected. Undoubtedly, however, the flavonols will circulate in the plasma mainly as glucuronide and sulphate conjugates. These metabolites will have different biological effects to the aglycone and parent glycoside, and thus should be the focus of future research.

\section{Acknowledgements}

We would like to thank the Biotechnology and Biological Sciences Research Council for support (studentship AJD). 


\section{References}

Aziz AA, Edwards CA, Lean MEJ \& Crozier A (1998) Absorption and excretion of conjugated flavonols, including quercetin $4^{\prime}$ $O$ - $\beta$-glucoside and isorhamnetin $4^{\prime}-O$ - $\beta$-glucoside, by human volunteers. Free Radical Research 29, 257-269.

Baba S, Furuta T, Fujioka M \& Goromaru T (1983) Studies on drug-metabolism by use of isotopes XXVII: urinary metabolites of rutin in rats and the role of intestinal microflora in the metabolism of rutin. Journal of Pharmaceutical Sciences 72, 1155-1158.

Baba S, Furuta T, Horie M \& Nakagawa H (1981) Studies on drug metabolism by use of isotopes XXVI: determination of urinary metabolites of rutin in humans. Journal of Pharmacological Science 70, 780-782.

Bourne LC \& Rice-Evans CA (1998) Urinary detection of hydroxycinnamates and flavonoids in humans after high dietary intake of fruit. Free Radical Research 28, 429-438.

Bourne LC \& Rice-Evans CA (1999) Detecting and measuring bioavailability of phenolics and flavonoids in humans: pharmacokinetics of urinary excretion of dietary ferulic acid. Methods in Enzymology 299, 91-106.

Crespy V, Morand C, Besson C, Manach C, Démigné C \& Rémésy C (1999b) Intestinal metabolism of quercetin 3-Oglucose in rats. SFRR Europe Winter Meeting: Bioflavonoids and polyphenols in health and disease, Dinard, France, P002.

Crespy V, Morand C, Manach $\mathrm{C}$, Besson $\mathrm{C}$, Démigné $\mathrm{C} \&$ Rémésy C (1999a) Part of quercetin absorbed in the small intestine is conjugated and further secreted in the lumen. American Journal of Physiology 277, G120-G126.

Day AJ, Cañada FJ, Díaz JC, Kroon PA, Mclauchlan R, Faulds CB, Plumb GW, Morgan MRA \& Williamson G (2000) Dietary flavonoid and isoflavone glycosides are hydrolysed by the lactase site of lactase phlorizin hydrolase. FEBS Letters 468, 166-170.

Day AJ, DuPont MS, Ridley S, Rhodes M, Rhodes MJC, Morgan MRA \& Williamson G (1998) Deglycosylation of flavonoid and isoflavonoid glycosides by human small intestine and liver $\beta$-glucosidase activity. FEBS Letters 436, 71-76.

deVries JHM, Hollman PCH, Meyboom S, Buysman MNCP, Zock PL, van Staveren WA \& Katan MB (1998) Plasma concentrations and urinary excretion of the antioxidant flavonols quercetin and kaempferol as biomarkers for dietary intake. American Journal of Clinical Nutrition 68, 60-65.

Gee JM, DuPont MS, Rhodes MJC \& Johnson IT (1998) Quercetin glucosides interact with the intestinal glucose transport pathway. Free Radical Biology and Medicine 25, $19-25$.

Gee JM, DuPont MS, Day AJ, Plumb GW, Williamson G \& Johnson I (2000) Uptake of quercetin glycosides involves deglycosylation and interaction with the sodium-dependent glucose transport pathway in rat small intestine. Journal of Nutrition 130, 2765-2771.

Hirayama BA, Lostao MP, Panayotova-Heiermann M, Loo DD, Turk E \& Wright EM (1996) Kinetic and specificity differences between rat, human, and rabbit $\mathrm{Na}^{+}$- glucose cotransporters (SGLT-1). American Journal of Physiology 270, G919-G926.

Hollman PCH, Buysman MNCP, van Gameren Y, Cnossen EPJ, deVries JHM \& Katan MB (1999) The sugar moiety is a major determinant of the absorption of dietary flavonoid glycosides in man. Free Radical Research 31, 569-573.

Hollman PCH, van Trijp JMP \& Buysman MNCP (1996) Fluorescence detection of flavonols in HPLC by postcolumn chelation with aluminium. Analytical Chemistry 68, 3511-3515.

Hollman PCH, van Trijp JMP, Buysman MNCP, Gaag MS, Menglers MJB, deVries JHM \& Katan MB (1997) Relative bioavailablity of the antioxidant quercetin from various foods in man. FEBS Letters 418, 152-156.

Ioku K, Pongpiriyadacha Y, Konishi Y, Takei Y, Nakatani N \& Terao J (1998) $\beta$-Glucosidase activity in the rat small intestine towards quercetin monoglucosides. Bioscience Biotechnology Biochemistry 62, 1428-1431.

Janseen PLTM, Mensink RP, Cox FJJ, Harryvan JL, Hovenier R, Hollman PCH \& Katan MB (1998) Effects of the flavonoids quercetin and apigenin on hemostasis in healthy volunteers: results from an in vitro and a dietary supplement study. American Journal of Clinical Nutrition 67, $255-262$.

Lambert N, Kroon PA, Faulds CB, Plumb GW, McLauchlan WR, Day AJ \& Williamson G (1999) Purification of cytosolic betaglucosidase from pig liver and its reactivity towards flavonoid glycosides. Biochimica et Biophysica Acta - Protein Structure and Molecular Enzymology 1435, 110-116.

Lostao MP, Hirayama BA, Loo DDF \& Wright EM (1994) Phenylglucosides and the $\mathrm{Na}^{+} /$glucose cotransporter (SGLT1) analysis of interactions. Journal of Membrane Biology 142, $161-170$.

Mabry TJ, Markham KP \& Thomas MB (1970) The Systematic Identification of Flavonoids. New York: Springer-Verlag.

Manach C, Morand C, Crespy V, Démigné C, Texier O, Regerat F \& Rémésy C (1998) Quercetin is recovered in human plasma as conjugated derivatives which retain antioxidant properties. FEBS Letters 426, 331-336.

Manach C, Morand C, Démigné C, Texier O, Régérat F \& Rémésy C (1997) Bioavailability of rutin and quercetin in rats. FEBS Letters 409, 12-16.

Mauri PL, Iemoli L, Gardana C, Riso P, Simonetti P, Porrini M \& Pietta PG (1999) Liquid chromatography/electrospray ionization mass spectrometeric characterization of flavonol glycosides in tomato extracts and human plasma. Rapid Communication in Mass Spectrotrometry 13, 924-931.

Mizuma T \& Awazu S (1998) Inhibitory effect of phloridzin and phloretin on glucuronidation of $p$-nitrophenol, acetaminophen and 1-naphthol: kinetic demonstration of the influence of glucuronidation metabolism on intestinal absorption in rats. Biochimica et Biophysica Acta - General Subjects 1425 . 398-404.

Morand C, Crespy V, Manach C, Besson C, Demigne C \& Rémésy C (1998) Plasma metabolites of quercetin and their antioxidant properties. American Journal of Physiology 44, R212-R219.

Morand C, Manach C, Crespy V \& Remesy C (2000) Quercetin 3-O-beta-glucoside is better absorbed than other quercetin forms and is not present in rat plasma. Free Radical Research 33, 667-672.

Paganga G \& Rice-Evans C (1997) The identification of flavonoids as glycosides in human plasma. FEBS Letters 401, 78-82.

Panayotova-Heiermann M, Loo DD, Kong CT, Lever JE \& Wright EM (1996) Sugar binding to $\mathrm{Na}^{+} /$glucose cotransporters is determined by the carboxyl-terminal half of the protein. Journal of Biological Chemistry 271, 10029-10034.

Park YK \& Lee CY (1996) Identification of isorhamnetin 4'glucoside in onions. Journal of Agricultural and Food Chemistry 44, 34-36.

Price KR, Prosser T, Richetin AMF \& Rhodes MJC (1999) A comparison of the flavonol content and composition in dessert, cooking and cider-making apples; distribution within the fruit and effect of juicing. Food Chemistry 66, 489-494.

Rivera-Sagredo A, Cañada FJ, Nieto O, Jimenez-Barbero J \& Martín-Lomas M (1992) Substrate-specificity of smallintestinal lactase - assessment of the role of the substrate 
hydroxyl-groups. European Journal of Biochemistry 209, $415-422$.

Saija A, Scalese M, Lanza M, Marzullo D, Bonina F \& Castelli F (1995) Flavonoids as antioxidant agents - importance of their interaction with biomembranes. Free Radical Biology and Medicine 19, 481-486.

Spencer JPE, Chowrimootoo G, Choudhury R, Debnam ES, Srai SK \& RiceEvans C (1999) The small intestine can both absorb and glucuronidate luminal flavonoids. FEBS Letters 458, 224-230.
Williamson G, Plumb GW, Uda Y, Price KR \& Rhodes MJC (1996) Dietary quercetin glycosides: antioxidant activity and induction of the anticarcinogenic phase II marker enzyme quinone reductase in Hepalclc7 cells. Carcinogenesis 17, 2385-2387.

Young JF, Nielsen SE, Haraldsdottir J, Daneshvar B, Lauridsen ST, Knuthsen P, Crozier A, Sandstrom B \& Dragsted LO (1999) Effect of fruit juice intake on urinary quercetin excretion and biomarkers of antioxidant status. American Journal of Clinical Nutrition 69, 87-94. 